\title{
Ideational agraphia: a single case study
}

\author{
DOREEN M BAXTER, ELIZABETH K WARRINGTON
}

From the National Hospital for Nervous Diseases, London, UK

SUMMARY A case study investigates the writing, spelling and praxic skills of one patient who was found to have a selective impairment in his ability to write letters and words in the absence of difficulty in copying these same letters and words. He appeared to have difficulty accessing the correct motor programmes or sequences for writing which we term "ideational agraphia" analagous to the syndrome of ideational apraxia. These findings are related to Margolin's informationprocessing model of writing.

The concept of "pure agraphia" as a unitary syndrome has long been superseded by the documentation of a number of distinct subtypes of agraphia. Inherent in an accurate classification of the agraphias is the distinction between the disorders of "spelling" and disorders of "writing". In the spelling agraphias there is a disturbance of letter choice but the actual written form of letters remains intact. The majority of these cases show little or no difference between oral and written spelling skills, unless associated deficits are also present. In contrast, patients with disorders of writing or apraxic agraphia do not have problems with letter-name selection as such. The deficit cannot be explained by peripheral weakness or clumsiness, by sensory problems or by confusion or impaired reasoning. The identification of "pure" apraxic agraphia requires a disturbance of writing in the absence of a disturbance of spelling, reading or other general language problems. More importantly, it should occur in the absence of major praxic or visuo-constructional difficulties.

To our knowledge, no reports providing quantitative data fulfilling the above criteria have been published (for a review see ref 1 ), although there are a number of cases which include apraxic agraphia as a major feature (for example, in refs 2-5, amongst others). The following systematic investigation describes a patient with a marked disturbance of writing in the absence of any impairment of oral spelling, praxic or visuo-constructional difficulties, thus fulfilling the above requirements of a "pure" apraxic agraphic.

Address for reprint requests: DM Baxter, The National Hospital for Nervous Diseases, Queen Square, London WCIN 3BG, UK.

Received 25 June 1985 and in revised form 24 August 1985. Accepted 1 September 1985

\section{Case report}

IDT, a 73-year-old retired production engineer was transferred for further investigations on 2 May 1985 . He was fully right handed for writing and for all tasks involving both motor agility and motor power. Since December 1984 he had experienced increasing difficulties with memory, his conversation had become "woolly" and he had even lost his way when driving in a familiar district. His writing had deteriorated and since March he had been unable to write at all.

On examination there was no evidence of papilloedema or visual field loss. His cranial nerves, motor system and reflexes were all normal. No definite sensory loss was present although two-point discrimination was a little variable on the right hand (right index finger $5 \mathrm{~mm}$, left $4 \mathrm{~mm}$ ). He was, however, totally disorientated in time and place. He was unable to give a history and had forgotten his home address. Apart from his very obvious global memory impairments he had an agraphia without dyslexia. A detailed account of his cognitive deficits is given below.

His MRI scan (fig 1, a, b) showed "a large mass lesion situated deep in the parieto-occipital region on the left, with surrounding changes in the deep white matter extending through the septum of the corpus callosum to involve the right cerebral hemisphere". It was felt that the surrounding and contralateral changes could be due to oedema but infiltration could not be excluded. There was general agreement that the tumour was a glioma and IDT was treated conservatively and referred for radiotherapy. A mild diabetic condition was discovered for which a diet was recommended.

\section{Psychological test findings}

IDT's test scores are summarised in table 1: he scored at a bright average level on verbal tests and at an average level on nonverbal tests on the WAIS. All his subtest scores fell within the average range with the exception of his superior score on Vocabulary. His average nonverbal IQ was indeed creditable in view of evidence of patchy right-sided neglect when completing the performance subtests. His recognition memory for visual and most especially verbal material was impaired. ${ }^{6}$ With the exception of his performance on a dot counting test, his performance on spatial and perceptual tests 

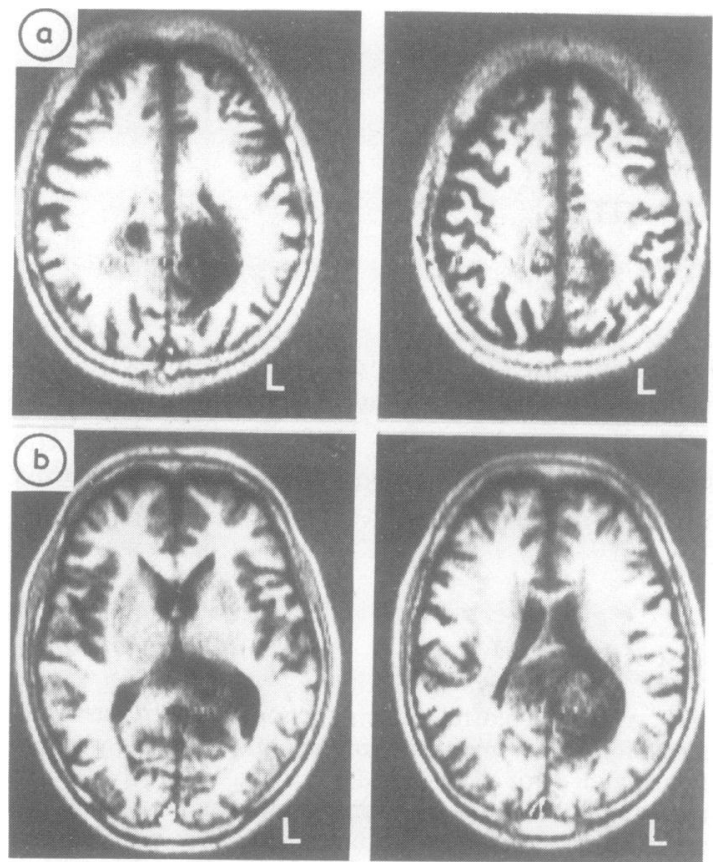

Fig $1 a, b . M R I$ scan reported to be a left parieto-occipital lesion extending through the corpus callosum to the right hemisphere.

was entirely satisfactory. ${ }^{78} \mathrm{He}$ tended to underestimate the random arrays of dots suggesting a degree of right-sided visual inattention. His copy of a cube and star was unremarkable. His drawing of the Rey-Osterreith ${ }^{9}$ complex design was reasonable and apart from two minor omissions, there were no spatial or constructional errors in his copy (see fig 2). His praxic skills were unremarkable and he was able to copy simple hand movements and learn a more complex sequence of three hand positions following Kimura's procedures. ${ }^{10}$ His speech was fluent, ${ }^{11}$ well articulated, without evidence of nominal dysphasia. ${ }^{12}$ His reading ${ }^{13}$ was intact and in addition he was also able to name visually-presented letters accurately and select letters from an array, given their alphabet name. Oral spelling was also intact, falling between the $60-70$ th percentile. ${ }^{14}$ However, he was unable to write any of these same words. At no point was he observed to use

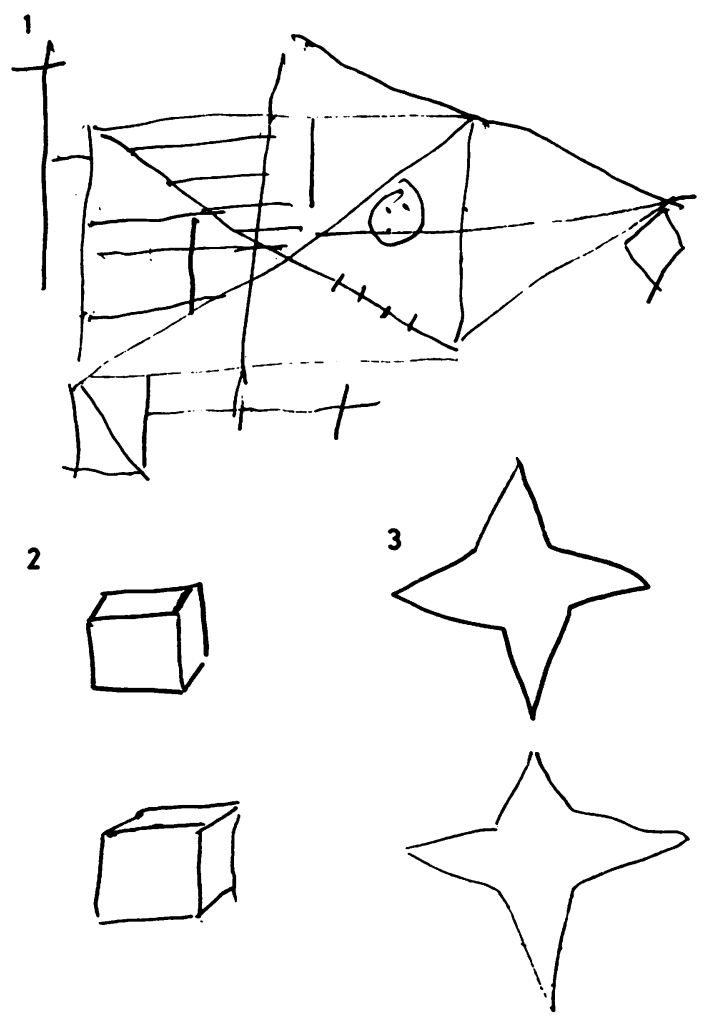

Fig 2 IDT's copy of (1) Rey-Osterreith design, (2) Cube, (3) Star.

his left hand for writing and no attempt was made to assess "left-handed writing". It was this marked discrepancy between intact oral spelling and impaired writing, in the absence of aphasia, dyslexia, limb apraxia or constructional difficulties which prompted the present more detailed investigation of his graphic and praxic skills. The testing was carried out over five sessions between 7-13 May 1985.

\section{EXPERIMENTAL TESTS}

Representation of symbols

IDT first attempted to write all the letters of the alphabet to dictation in block capitals followed by the same letter in

Table 1 Individual scores on verbal and nonverbal tests

\begin{tabular}{lllr}
\hline Verbal & & Nonverbal & $=102$ \\
\hline WAIS Verbal IQ & $=115$ & WAIS Performance IQ & 11 \\
$\quad$ Arithmetic & $=11$ & Picture Completion & $=$ \\
$\quad$ Similarities & $=13$ & Block Design & $=8$ \\
$\quad$ Digit Span & $=13$ & Picture Arrangement & $=35 / 50$ \\
$\quad$ Vocabulary & $=15$ & Recognition Memory: Faces & $=14 / 20$ \\
Recognition Memory: Words & $=25 / 50$ & Unusual Views & $=10 / 10$ \\
Graded Naming Test & $=22 / 30$ & Dot Centre & $=6 / 10$ \\
Fluency "S", 1 1/2 min & $=22$ & Dot Counting & \\
Reading Quotient (NART) & $=114$ & Albert's visual search & \\
Oral Spelling A & $=23 / 30$ & (29 s) errorless & \\
Oral Spelling B & $=22 / 30$ & &
\end{tabular}


script (presented in random order). On two further occasions he was required to write the letters in capitals and on another two occasions in script (presented in random order). Thus all letters were attempted three times in their capital and script form. Each letter was marked correct if it could be accurately recognised by an independent judge. The number of capital and script letters written correctly is given in table 2 . At his best IDT was never able to write more than half the letters in capitals and less than a third in script at any one time.

The consistency of his attempts to write these letters is shown in table 3 . On all three occasions he successfully wrote five letters in the capital form and one in script; on two occasions he wrote five capitals and four script letters and on one occasion seven capital and nine script letters. Even the nine capital letters which were failed consistently on all three occasions were spontaneously written correctly at other times. His error responses were quite variable and the same error was not repeated on other occasions. His most frequent error when attempting to write capitals consisted of letterlike substitutions, similar to, but not always identical to the letter "I" $(36 \%)$. Other errors consisted of letter substitutions, incomplete letters and figures that looked like a combination of two letters. Most errors in script were also letter substitutions or approximations to letters, the most frequent being similar, but not always identical, to the letter "a" (18\%) (fig 3).

IDT was given a list of capital letters (in random order) and was asked to write the equivalent script form for each. Similarly, he was given a list of script letters and asked to write these in capitals. In transforming capitals to script he scored $7 / 26$ correct and for transforming script to capitals his score was $8 / 26$ correct which is comparable with his inability to write script letters to dictation (fig 4).

In contrast, he was able to copy both upper and lower case letters almost entirely accurately. This task was attempted on two separate occasions. The only minor inaccuracies were that on one occasion $Q$ was written as a three-quarter circle, the final loop of lower case $\mathrm{g}$ was omitted and $\mathrm{H}$ began as a $T$ before being self-corrected. Examples of letters written to dictation and copied are shown in fig 3.

IDT's inability to write to dictation with the preservation of copying, demonstrated for individual letters, was equally clear for words. Thus his ability to write words to dictation either in print or script was so severely impaired that we have no examples of a single legible word in our corpus. In contrast his ability to copy words in both upper and lower case was entirely satisfactory (fig 5).

On three occasions he attempted to write the numbers one to nine to dictation (randomly presented). His score on each occasion is given in table 2 . On the whole he wrote numbers more accurately with the exception that on one occasion he persisted in writing letters when numbers were required. As with letters and words, his ability to write numbers from a

Table 2 Number of capital letters, script letters and digits correctly written to dictation on three occasions

\begin{tabular}{lccc}
\hline Trial & Ist & 2nd & 3rd \\
\hline Alphabet-Capitals & $10 / 26$ & $10 / 26$ & $13 / 26$ \\
Alphabet-Script & $7 / 26$ & $8 / 26$ & $8 / 26$ \\
Digits (1-9) & $8 / 9$ & $1 / 9$ & $5 / 9$ \\
\hline
\end{tabular}

Table 3 Consistency of writing letters to dictation

\begin{tabular}{lll}
\hline $\begin{array}{l}\text { No times } \\
\text { correct }\end{array}$ & Capitals & Lower-case script \\
\hline 3 & I, J, S, T, O. & s. \\
2 & A, C, G, K, U. & e, a, w, z. \\
1 & B, H, L, V, W, X, Z. & b, f, i, l, n, p, q, r, w. \\
0 & D, E, F, M, N, P, Q, R, Y. & c, d, g, h, j, k, m, o, t, u, v, y. \\
\hline
\end{tabular}

model was entirely satisfactory and on three occasions he copied them without error.

IDT was unable to draw a plus or minus sign on request despite his errorless copies when provided with a model. On the other hand he successfully drew a multiplication and a division sign on request. He was also able to draw a diamond without a model but failed in his attempts to represent a club, heart or spade on request. These latter symbols were copied accurately with the exception of the club sign which was drawn upside down.

\section{Oral description of letters}

An attempt was made to assess whether IDT could image capital letters. He first classified each letter as "having a

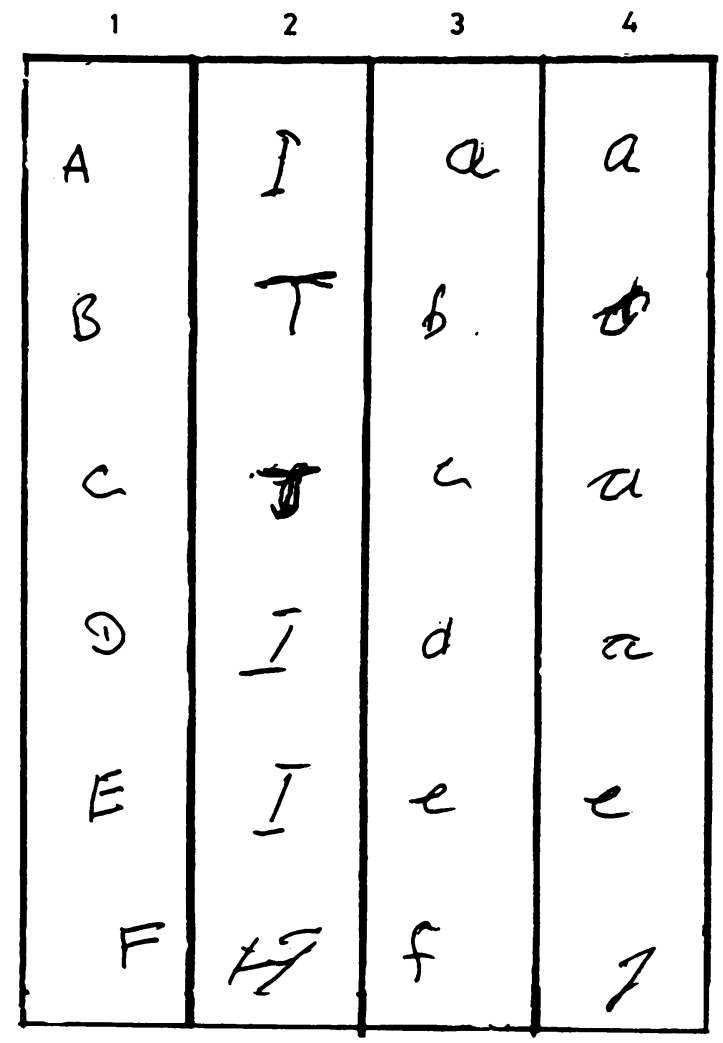

Fig 3 Copying and writing letters to dictation (1) Upper case: copy (2) Upper case: to dictation (3) Lower case: copy (4) Lower case: to dictation. 
1

2

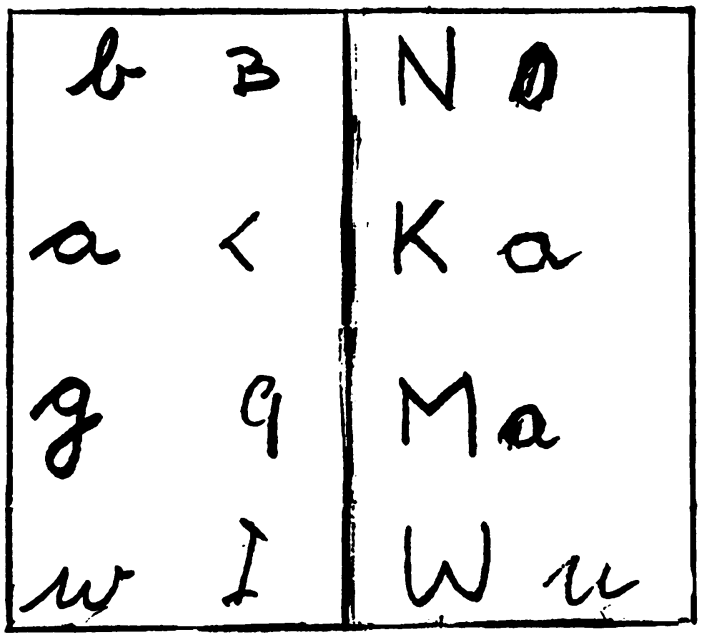

Fig 4 IDT's attempts to transform letters (1) from script to capitals (2) from capitals to script.

curve" or "no curve". He then classified the latter as "having an oblique" or "no oblique". His responses were entirely correct with the exception of $\mathrm{W}$ which was classified as having no oblique lines. He was also asked to describe in detail ten capital letters, some of which were correct in every detail $(6 / 10)$, for example, " $R$ - a vertical line and adjacent to that two parts; one of the parts is a circle".

PRAXIC SKILLS

In view of IDT's marked graphic difficulties a more detailed investigation was made of his other praxic skills. For all these tasks two independent judges scored IDT's responses.

\begin{tabular}{|c|c|}
\hline $\begin{array}{rrr}0_{\text {ON }} & \text { HIS } \\
\text { ON WAY }\end{array}$ & (b) 1 int is \\
\hline $\begin{array}{l}\text { on his way } \\
\text { on his way }\end{array}$ & $350194 \operatorname{cn}$ \\
\hline $\begin{array}{l}\text { SHOE SHOE } \\
\text { FLOOD FLOOD }\end{array}$ & $\begin{array}{l}\text { ¿SUCL } \\
\text { 51 UGCLS }\end{array}$ \\
\hline
\end{tabular}

Fig 5 Copying and writing words to dictation (a) copy (b) to dictation:- 1. script, 2. lower case, 3. upper case, 4. and 5. unspecified.

\section{(a) Utilisation of objects or ideational apraxia}

Ten objects were presented together and IDT was required to select and correctly show the use of each object to command. His performance was errorless. The following objects were used:- 1 . scissors, 2 . hammer, 3. toothbrush, 4. eraser, 5. screwdriver, 6. key, 7. comb, 8. knife, 9. razor, 10. paperclip.

\section{(b) Ideomotor apraxia}

IDT was asked to perform the following gestures:- 1 . salute, 2. wave, 3. threaten, 4. hitchhike, 5. blow a kiss, 6. scratch his head, 7. victory sign, 8 . indicate someone is crazy, 9. snap fingers, 10. sign of the cross. With the exception of his attempt to produce the sign of the cross which was performed hesitantly, all other movements were quickly and efficiently executed.

\section{(c) Organisation of more complex movement sequences}

IDT was asked to carry out the following actions, being provided with the necessary real objects:- 1 . fold a piece of paper and put it in an envelope, 2. light a candle and blow it out, 3. tie a bow in a laced shoe, 4. wrap a box in brown paper with sellotape, 5 . put a pencil in a compass and draw a circle, 6. buckle a belt, 7. use a hammer and nail, 8. use a bicycle pump, 9. make holes in paper with a punch, 10. make a cup of hot coffee. His performance was unremarkable on all these tasks, with the notable exception of his failure to buckle a belt which he failed after two attempts and succeeded only when he put the belt around his own waist.

\section{(d) Visuo-constructional tasks}

IDT was asked to draw the following twenty-four different objects from memory:- apple, arrow, church, pipe, bath, chair, car, cat, flower, table, basket, shoe, wine bottle, TV, crescent moon, tree, sun, boat, umbrella, house, cup, window, kit, saucepan. The first twelve were attempted on 8 May 1985 when he scored $8 / 12$ correct and the latter twelve on 9 May 1985 when he scored 7/12 correct. Each drawing was considered as correct if the object could be identified by two independent judges. There was total agreement between the judges despite the great variability in the quality of IDT's drawings which was somewhat better on the first than the second occasion. His best drawings are illustrated in fig 6 to be compared with two which were not recognised by the judges.

\section{Discussion}

Discussion of the anatomical substrate of IDT's deficits is clearly inappropriate in the context of bilateral cerebral pathology. Rather we wish to emphasise the striking cognitive dissociations which are worthy of detailed analysis in their own right. The present case describes an investigation of a patient with severe apraxic agraphia. IDT's language skills and oral spelling appeared intact but he was totally unable to write even the simplest high frequency three-letter word. The main point of interest is the occurrence of severe apraxic agraphia in the context of preserved praxic and constructional skills. Particularly striking is the 

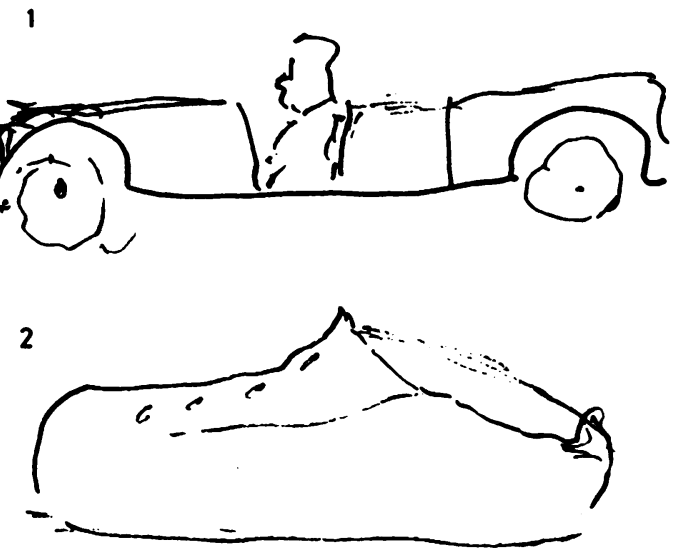

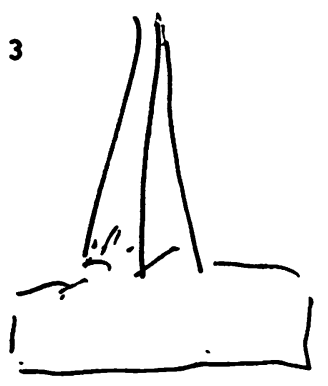

4

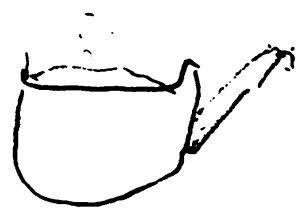

Fig 6 IDT's drawings of (1) car (2) shoe (3) church (4) pipe.

dissociation between his ability to copy letters and his attempts to write them to dictation. Thus he was capable of executing the appropriate movement patterns when copying but was unable to execute them without a model. To our knowledge this is the first quantitative documentation of a selective writing disorder or apraxic agraphia occurring in the context of the preservation of other related skills.

It might be argued that the variability in the quality of IDT's drawing from memory is similar to the variability in his writing to dictation and thus his difficulties represent a single high level impairment in the organisation of graphic skills. However, for the average person writing represents an over-learned skill performed with little thought as to the motor form of the letters, providing they can spell the word. On the other hand for most people drawing is a novel task involving more active organisation. Were it not for the high quality of some of IDT's drawings, most of his spontaneous attempts would merely have been accepted as those of a "poor drawer". In contrast, his difficulty with writing is of an entirely different order of magnitude to that of the "poor writer" or even the illiterate. We would argue that the high-level organisational difficulties occasionally seen in drawing represent an independent and much milder deficit compared with his difficulties with writing.

In classifying disorders of movement, a distinction is often drawn between motor apraxia and ideational apraxia. ${ }^{1516}$ The motor apraxic is unable to execute novel movements to command but has no difficulty in executing well-learned familiar motor sequences. In contrast, the ideational apraxic may be able to learn and copy novel movements but is impaired in executing familiar or over-learned motor sequences. This distinction between a motor and ideational apraxic would appear to be equally appropriate for the apraxic agraphic syndromes. A motor apraxic would be identified when there is a more general impairment in carrying out the sequence of movements necessary for writing, and when there is as much difficulty in copying as in writing letters to dictation, albeit of poor quality. The primary difficulty would thus not be at the level of access to the movement patterns per se but in the execution of the letter form which is slow and laborious, as if the automaticity or motor fluency is impaired. In contrast, the ideational agraphic would be identified when access to the appropriate motor programmes or sequences necessary for producing the letter form is impaired. We suggest that by providing a model the necessity to access the appropriate motor sequence is bypassed and the execution can be achieved at a "pictorial" level. ${ }^{17}$ This form of agraphia would be identified when there is disproportionate difficulty in writing to dictation as compared to copying when provided with a model. Adopting this terminology, we suggest that our patient has a very selective ideational agraphic syndrome. Like the ideational apraxic, he was unable to execute over-learned movement patterns for writing on request but he had no difficulty with comparable copying tasks. Although Goldstein ${ }^{18}$ anticipated the distinction between ideational and motor agraphia, he did not consider the former to be a "pure" syndrome. In his view it was invariably associated with letterrecognition deficits and a degree of impairment in copying. This is clearly not the case for our patient, IDT.

Margolin ${ }^{1}$ has proposed a comprehensive information-processing model of the writing process which appears to be most relevant to the formulation of IDT's agraphia (fig 7). Our patient showed correct letter selection or "orthographic buffer" in his intact oral spelling. IDT was also able to select correctly letters from a visual array, when given the alphabet name, thus providing evidence to support an intact "physical letter code". The two components of the model that appear directly relevant to the present case refer to the "graphic motor pattern"17 and the "graphic code". The former is analogous to the concept of motor engrams" 19 and defined as a "store of 


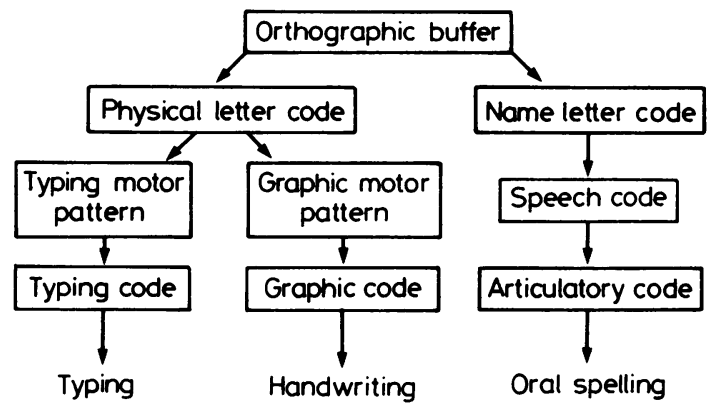

Fig 7 A model of cognitive processes in spelling, peripheral aspects. (With permission after Margolin, ${ }^{1}$ ).

motor programmes which specify the sequence of strokes necessary to complete the form dictated by the physical code". 1 The latter or final stage in handwriting "translates information from the graphic pattern into specific neuromuscular instructions", specifying the particular muscle group, amount of force and speed necessary for handwriting.

Our patient's inability to write to dictation in the context of the preservation of his copying skills suggests that his difficulty is not at this final stage of motor output or the "graphic code", but occurs at the level which specifies the motor sequences or "graphic motor pattern". Thus IDT provides support for Margolin's model and the distinction he makes between the two levels of motor output necessary for writing. Whether IDT has difficulty accessing the graphic motor pattern or whether there is a degradation of the store itself remains an open question.

We are grateful to Dr J Morgan Hughes for permission to investigate IDT and to report our findings.

\section{References}

${ }^{1}$ Margolin DI. The neuropsychology of writing and spelling. Semantic, phonological, motor and perceptual processes. QJ Exp Psychol 1984;36A:459-89.

${ }^{2}$ Zangwill OL. Agraphia due to a left parietal glioma in a left-handed man. Brain 1954;77:510-20.

${ }^{3}$ Kapur K, Lawton NF. Dysgraphia for letters: a form of motor memory deficit. J Neurol Neurosurg Psychiatry 1983;46:573-5.

${ }^{4}$ Roeltgen DP, Heilman KM. Apractic agraphia in a patient with normal praxis. Brain Lang 1983;18:35-46.

${ }^{5}$ Margolin DI, Binder L. Multiple component agraphia in a patient with atypical cerebral dominance: an error analysis. Brain Lang 1984;22:26-40.

${ }^{6}$ Warrington EK. Recognition Memory Test. Windsor, England: NFER-Nelson Publishing Co Ltd. 1984.

${ }^{7}$ Whiteley AM, Warrington EK. Prosopagnosia: A clinical, psychological and anatomical study in three patients. $J$ Neurol Neurosurg Psychiatry 1977;40:395-403.

${ }^{8}$ Albert ML. A simple test of visual neglect. Neurology (Minneap) 1973;23:658-64.

${ }^{9}$ Osterreith PA. Le test de copie d'une figure complexe. Arch Psychologique 1944;30:206-356.

${ }^{10}$ Kimura D. Neuromotor mechanisms in the evolution of human conditioning. In: Steklis HD, Raleigh MJ. eds. Neurobiology of social communication in primates. New York: Academic Press 1979:197-219.

${ }^{11}$ Coughlan AK, Warrington EK. Word comprehension and word retrieval in patients with localised cerebral lesions. Brain 1978;101:163-85.

12 McKenna P, Warrington EK. Graded Naming Test. Windsor, England: NFER-Nelson Publishing Co Ltd. 1983.

${ }^{13}$ Nelson HE. National Adult Reading Test. Windsor, England: NFER-Nelson Publishing Co Ltd. 1982.

${ }^{14}$ Baxter DM. The development of a graded spelling test for adults. International Neuropsych Soc, European Conference, Deauville, France. INS Bulletin March Ann Arbor 1982, 34.

${ }^{15}$ De Renzi E, Pieczuro A, Vignolo LA. Ideational apraxia: a quantitative study. Neuropsychologia 1968;6:41-52.

${ }^{16}$ Lehmkuhl G, Poeck K, Willmes K. Ideomotor apraxia and aphasia: An examination of types and manifestations of apraxic symptoms. Neuropsychologia 1983;21: 199-212.

${ }^{17}$ Ellis AW. Spelling and writing (reading and speaking). In: AW Ellis ed. Normality and pathology in cognitive functions. London: Academic Press. 1983.

${ }^{18}$ Goldstein K. Language and Language Disturbances. New York: Grune \& Stratton, Waverly Press. 1948.

${ }^{19}$ Heilman KM, Coyle JM, Gonyea EF, Geschwind N. Apraxia and agraphia in a left-hander. Brain 1973;96: 21-28. 